\title{
P-glycoprotein Expression in Solid Tumors - An Analysis
}

\author{
Kakuli Chakraborty, Pratiti Ghosh* \\ Department of Physiology, West Bengal State University, Kolkata, West Bengal, INDIA.
}

\begin{abstract}
P-glycoprotein is an efflux transporter belonging to the ATP Binding Cassette $(A B C)$ family of transporters and is encoded by Multidrug resistance (MDR1) gene. It is primarily involved in efflux of xenobiotics that permeate the external boundaries into the tissues. Chemotherapeutics are target oriented drugs for destruction of malgrowing cells to combat critical illness (viz., cancer, AIDS, malaria, tuberculosis, etc.) which are thus interpreted as harmful by the MDR system. This might cause overexpression of p-glycoprotein in such organs. Overexpression of p-glycoprotein rather than up-regulation of $\mathrm{ABC}$-transporters are associated with resistance of tumours to multiple chemotherapeutic agents, thus reducing their bioavailability in the specific organs. The present review thus attempts to coalesce this expression data in solid tumors which maybe intrinsic to the organ or an after-effect of chemotherapy, thus altering the pharmacodynamics of drug permeation. For this purpose, peer reviewed publications have been analysed to delineate the range of fluctuation in p-glycoprotein expression in different organs after therapeutic intervention. It is extensively distributed and highly overexpressed in all neural tumors,
\end{abstract}

reproductive and genito-urinary cancer, sarcomas, oral squamous cell carcinoma, NSCLC, hepatocellular carcinoma, cholangiocarcinoma, pancreatic tumor, etc. On the other hand, p-glycoprotein expression in cancer of the larynx, small cell lung carcinoma (SCLC), osteosarcoma, rhabdosarcoma, often show substantial decrease in expression, though not in all studies. There was no consistent increase or decrease in p-glycoprotein expression in all the tumors.

Key words: P-glycoprotein, Solid Tumors, Chemotherapy, Upregulation, Downregulation.

Correspondence

Pratiti Ghosh,

Department of Physiology, West Bengal State University, Kolkata-700126, West Bengal, INDIA

Email id: pratitig@wbsu.ac.in

DOI: 10.5530/ijpi.2021.4.61

\section{INTRODUCTION}

Tumor or malignancy afflicts all human organs of all ages, where hepatoblastoma and hepatocellular carcinoma are common in children. Solid tumors are non-haematopoietic in origin and may be differentiated into epithelial tumors and sarcomas which account for about $90 \%$ of the solid tumors. Children are also at risk for congenital tumors of the adrenal gland (neuroblastoma), kidney (Wilm's tumor), muscle (rhabdomyosarcoma) and retina (retinoblastoma).

Treatment of these include surgery, radiation and/or chemotherapy, where the last procedure involving system-wide drug administration, is most effective against metastatic tumours. However, multidrug resistance (MDR) impedes successful chemotherapy, which is primarily mediated via an efflux transporter p-glycoprotein, (encoded by ATPbinding cassette sub-family B member 1 ( $A B C B 1$ ) gene or $M D R 1$ gene). Structurally, it is a $170 \mathrm{kDa}$ transmembrane glycoprotein (N-terminal glycosylation), comprised of two ATP-binding sites in the cytoplasmic domain. It is physiologically distributed in organs functionally involved with the external environment viz., the intestinal epithelium, hepatocytes, renal proximal tubular cells and adrenal gland for expulsion of xenobiotics. Its expression in capillary endothelial cells of the bloodbrain, blood-testis barrier and placenta indicate its relevance as 'gatekeeper', for conservation of the germ line and of the intrauterine embryo, thus preserving the internal milieu. ${ }^{1-3}$

This channel transports wide array of substrates ranging from drugs, chemotherapeutic agents, lipids, steroids, xenobiotics, peptides, bilirubin, cardiac glycosides, immunosuppressive agents, glucocorticoids, antiretroviral therapeutics, protease inhibitors and non-nucleoside reverse transcriptase inhibitors, with diverse molecular recognition adaptability.
In tumour cells, p-glycoprotein restricts intracellular drug concentrations, in the site of action. Its expression is upregulated in tumour cells transformed from tissues that express p-glycoprotein inherently (e.g., colon cancer) and in tumour cells transformed from tissues that do not normally express p-glycoprotein (e.g., breast cancer) after exposure to chemotherapeutic agents. As p-glycoprotein transports several chemotherapeutic agents, these tumours become resistant to the agent(s) administered and concurrently develop resistance to other chemotherapeutic agents that are p-glycoprotein substrates, resulting in MDR tumours. So, organ-based classification and inhibition of p-glycoprotein need research in anticipation of revival of sensitivity to chemotherapeutic agents.

There is a possible correlation between MDR1 gene or p-glycoprotein expression levels and the quantity of applied chemotherapy in different tumours. In cell cultures, cell viabilities decrease significantly without increase of MDR1 gene expression levels. Modulation of p-glycoprotein using chemosensitizers improves treatment efficacy in several types of tumour/cancer.

The present study aims to classify and analyze the MDR1/p-glycoprotein expression in different tumour specimens, with or without chemotherapy administration, based on data extracted from existing literature.

\section{METHODOLOGY}

About 255 online available peer-reviewed articles on p-glycoprotein / MDR1 expression in solid tumors were initially studied by both the authors. The search was obtained by enlisting all solid tumors and tagging "p-glycoprotein, chemotherapy" individually from 1988 till date, with each of them through "Pubmed" or "Google" search engine.

This is an open access article distributed under the terms of the Creative Commons Attribution-NonCommercial-ShareAlike 4.0 License, which allows others to remix, tweak, and build upon the work non-commercially, as long as the author is credited and the new creations are licensed under the identical terms. 


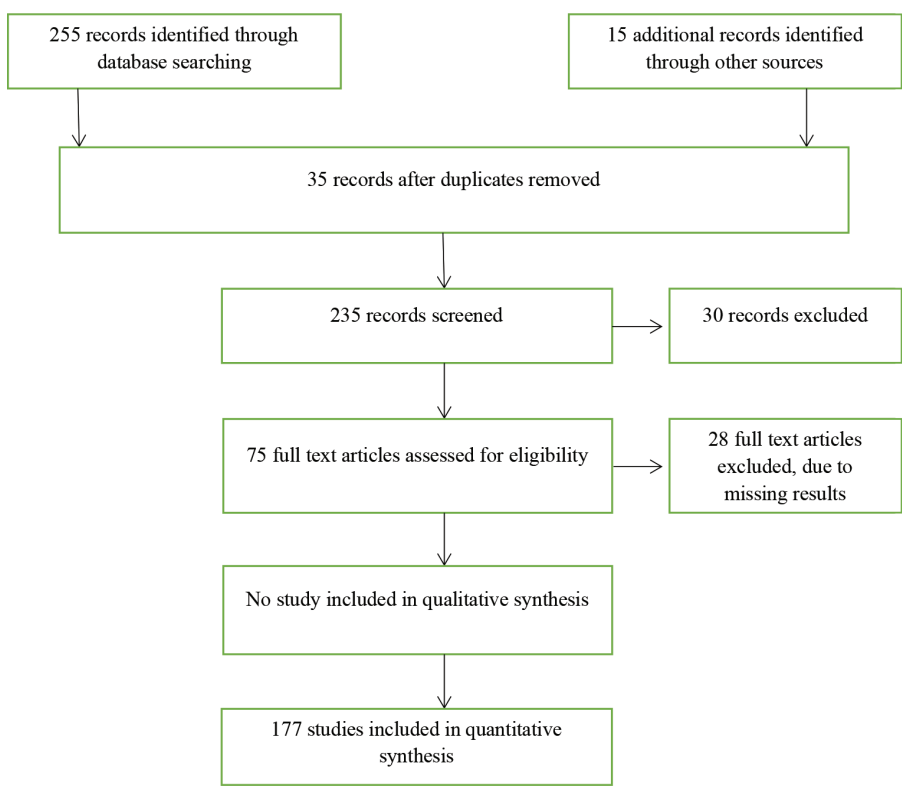

Figure 1: Flowchart of selection of relevant published articles.

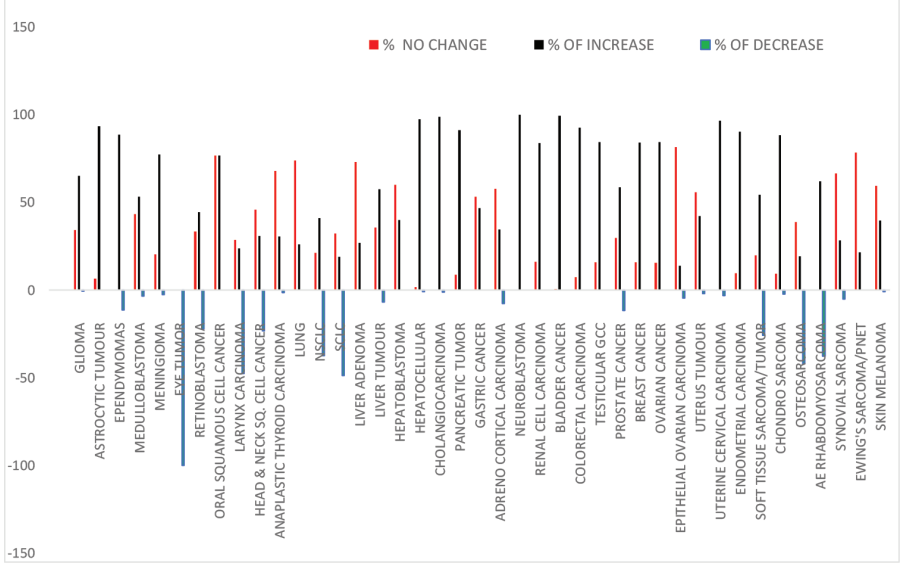

Figure 2: The percentage of increase / decrease / no alteration in the number of $\mathrm{p}$-glycoprotein receptors in different solid tumors in response to chemotherapy.

Of these, only 177 publications with quantitative numerical data were included in the study. These were considered for tabulation and data analysis by converting the obtained data into percentage scale. Those with undefined or qualitative results had to be excluded (Figure 1).

\section{RESULTS}

Analysis of online data from 177 studies were classified into three categories in accordance with increased, decreased or sparse change of expression of $m d r 1$ gene/p-glycoprotein in the organ tumors after chemotherapy administration. Such variation in p-glycoprotein expression as a result of therapeutic intervention has been demonstrated graphically based on the percentage of numerical values accumulated from available literature (Figure 2). There was no consistent increase or decrease in p-glycoprotein expression in all tumors. It is extensively distributed and highly overexpressed in all neural tumors, reproductive or urogenital cancer, sarcomas, oral squamous cell carcinoma, nonsmall cell lung carcinoma (NSCLC), hepatocellular carcinoma, cholangiocarcinoma, pancreatic tumor, melanoma, etc. In most other forms of cancer viz., gastric carcinoma, cancers of the thyroid, soft tissues, peripheral primitive neuroectodermal tumours (PNET), osteosarcoma, medulloblastoma, etc., it is primarily overexpressed in response to chemotherapy. On the other hand, p-glycoprotein expression in cancer of the larynx, small cell lung carcinoma (SCLC), osteosarcoma, rhabdosarcoma, often show substantial decrease in expression, though not in all studies. The bar diagram in Figure 2 provides an approximate idea regarding the upregulation and downregulation of p-glycoprotein receptors or $M D R 1$ gene in response to chemotherapy. It diagram shows that some organs show increase in receptor quantity after chemotherapy, indicating decreased chemosensitivity, i.e., the response to the drugs probably decreases when the aforesaid organs are affected by cancer. Drugs for cancer, malaria, AIDS and tuberculosis are complicated and complex in nature and resemble xenobiotics to a certain extent. This compels our physiological system to recognize these valuable curative drugs as potent harmful agents. The p-glycoprotein receptor analyzes and extrudes these chemotherapeutic drugs out of the cell in which it resides, thus resisting the therapy.

\section{DISCUSSION}

Though the sample sets were non-uniform and the results were an outcome of admixture of both in vitro and in vivo observations, yet there are broad areas of commonality. Overexpression of either of the MDR genes, MDR1 or Metal Resistance Protein (MRP), rather than up-regulation of $\mathrm{ABC}$-transporters, ${ }^{4}$ is associated with resistance of tumours to multiple chemotherapeutic agents. Downregulation of the receptors in response to a drug would imply chemosensitivity. There exist individualistic differences in chemotherapy sensitivity and expression of $M D R 1 .{ }^{5,6}$ It is often inversely related to the level of p-glycoprotein expression in inoperable tumours or its expression may not be of aggressive phenotype and thus not influence survival. ${ }^{7}$ Age, gender and physiological stage may all be contributory to the outcome. P-glycoprotein immunoreactivity was found to be less with advanced age in endometrial carcinoma but reverse in premenopausal patients. ${ }^{8}$ Its expression was observed to be minimal in less-differentiated ${ }^{9}$ and aggressive metastasis. ${ }^{10}$ Higher MDR1 expression in the invasive tumours compared with non-invasive tumours suggests that MDR1 expression and invasiveness may be linked. ${ }^{11}$

Non-uniformity in expression of p-glycoprotein in different tumors maybe attributed to multiple factors beyond the organ per se. Irradiation, ${ }^{12}$ radiotherapy, ${ }^{13}$ hyperthermia mediated by activation of $\mathrm{p} 38,{ }^{14}$ increased methylation, ${ }^{15}$ may singly or synergistically be contributory towards overt expression of p-glycoprotein thus inducing drug resistance. This may also be the result of a mechanism involving stabilization of a diverse group of mRNAs. ${ }^{16}$ The p-glycoprotein mRNA turnover rate is lower in tumours than in normal organs. ${ }^{17}$ MDR1 codon 3435 single nucleotide polymorphism at $\mathrm{C} / \mathrm{C}$ genotype has been observed to be chemosensitive to platinum-based therapy than patients with $\mathrm{C} / \mathrm{T}$ and $\mathrm{T} / \mathrm{T}$, without significant difference in overall survival. ${ }^{18}$ This is irrespective of the organ involved in chemosensitivity.

Expression of survivin and p-glycoprotein may be related to malignant tumour progression. ${ }^{19}$ There might be a correlation between loss of p53 function and expression of MDR. ${ }^{20} \mathrm{p} 53^{21}$ and $\mathrm{p} 27^{22}$ may be one of the active regulators of the MDR1 transcript and chemoresistance.

To circumvent this, alternative approaches comprising of new cytotoxic agents, gene directed applications ${ }^{23}$ through specifically directed adenoviral delivery of ribozymes ${ }^{24}$ or hurling of nano-therapeutic particles inside the cell per se maybe attempted. Knockdown of MDR1 significantly enhanced retention of the chemotherapeutics and decreased the efflux in MDR1-positive cells. $^{25}$ Modulation 
of p-glycoprotein may be achieved by co-administration with chemosensitizer inhibitor or modulator along with the substrate $e^{26-28}$ thus improving effectiveness of chemotherapy, especially in the highly differentiated tumours. Such simultaneous administration inhibits net intestinal absorption of therapeutics, altering their pharmacokinetics and therapeutic efficacy. ${ }^{29}$ Among others, RNA interference, ${ }^{30}$ transduction and expression of human TNF-alpha, ${ }^{31}$ transfection of hIL-2 gene ${ }^{32}$ can reverse expression of MDR1 mRNA and p-glycoprotein in the drug resistant cell line. ERK1, 2 and JNK, ${ }^{14}$ ROS acting as second messengers in tyrosine kinase signalling pathway may downregulate p-glycoprotein ${ }^{33}$ which may again instigate drug-resistant quiescent cells in tumors for cell-cycle activity. ${ }^{34}$

Correlating the efflux transporter expression with chemosensitivity might be beneficial as an independent prognostic molecular marker ${ }^{35}$ in the identification of individuals with multidrug resistance, to design alternately appropriate therapeutic modalities. ${ }^{36}$ However, MDR-1 mRNA is not a predictive of survival and metastatic progression does not coincide with MDR1 protein upregulation. ${ }^{37}$

\section{CONCLUSION}

The overall response of MDR1/p-glycoprotein suggests that in most tumours, chemoresistance far exceeds chemosensitivity, necessitating co-adminstration of nontoxic inhibitors, thus manipulating the drug efflux. The receptor expression is variable despite similarity in the type of tumour, indicating multifactorial regulation of the transporter. Quantitative studies on patients with complete follow-up for detailing expression of MDR1/p-glycoprotein and associated markers may help comprehend the contribution of these efflux pumps to the chemoresistance and address their predictive role. This will also help to formulate/administer drugs which shall circumvent p-glycoprotein mediated drug efflux.

\section{CONFLICT OF INTEREST}

The authors declare no conflict of interest.

\section{REFERENCES}

1. Sugawara I, Kataoka I, Morishita Y, Hamada H, Tsuruo T, Itoyama S, et al. Tissue distribution of P-glycoprotein encoded by a multidrug-resistant gene as revealed by a monoclonal antibody, MRK 16. Cancer Res. 1988;48(7):1926-9. PMID 2894894

2. Cordon-Cardo C, O'Brien JP, Casals D, Rittman-Grauer L, Biedler JL, Melamed $M R$, et al. Multidrug-resistance gene (P-glycoprotein) is expressed by endothelial cells at blood-brain barrier sites. Proc Natl Acad Sci U S A. 1989;86(2):695-8. doi: 10.1073/pnas.86.2.695, PMID 2563168.

3. Sasongko L, Link JM, Muzi M, Mankoff DA, Yang X, Collier AC, et al. Imaging P-glycoprotein transport activity at the human blood-brain barrier with positron emission tomography. Clin Pharmacol Ther. 2005;77(6):503-14. doi: 10.1016/j. clpt.2005.01.022, PMID 15961982

4. Eicher C, Dewerth A, Kirchner B, Warmann SW, Fuchs J, Armeanu-Ebinger $\mathrm{S}$. Development of a drug resistance model for hepatoblastoma. Int J Oncol. 2011;38(2):447-54. doi: 10.3892/ijo.2010.860, PMID 21132272.

5. Lopes JM, Bruland OS, Bjerkehagen B, Silva MC, Holm R, Pettersen EO, et al. Synovial sarcoma: immunohistochemical expression of P-glycoprotein and glutathione S transferase-pi and clinical drug resistance. Pathol Res Pract. 1997;193(1):21-36. doi: 10.1016/s0344-0338(97)80090-8, PMID 9112270.

6. Wei L, Song XR, Wang XW, Li M, Z Uo WS. Expression of MDR1 and GST-pi in osteosarcoma and soft tissue sarcoma and their correlation with chemotherapy resistance. Zhonghua Zhong Liu Za Zhi. 2006;28(6):445-8. PMID 17152492.

7. $\mathrm{Ng} \mathrm{IOL,} \mathrm{Liu} \mathrm{CL,} \mathrm{Fan} \mathrm{ST,} \mathrm{Ng} \mathrm{M.} \mathrm{Expression} \mathrm{of} \mathrm{P-glycoprotein} \mathrm{in} \mathrm{hepatocellular}$ carcinoma. A determinant of chemotherapy response. Am J Clin Pathol. 2000;113(3):355-63. doi: 10.1309/AC1M-4TY4-UOTN-EN7T, PMID 10705815.

8. Terek MC, Zekioglu O, Sendag F, Akercan F, Ozsaran A, Erhan Y. MDR1 gene expression in endometrial carcinoma. Int J Gynecol Cancer. 2003;13(5):673-7. doi: 10.1046/j.1525-1438.2003.13324.x, PMID 14675353

9. Nagasue N, Dhar DK, Makino Y, Yoshimura H, Nakamura T. Overexpression of P-glycoprotein in adenomatous hyperplasia of human liver with cirrhosis. J Hepatol. 1995;22(2):197-201. doi: 10.1016/0168-8278(95)80429-3, PMID
7540636

10. Witkowski JM, Kozłowska K, Zarzeczna M. Expression and activity of P-glycoprotein in transplantable hamster melanomas. Arch Dermatol Res. 2000;292(7):354-61. doi: 10.1007/s004030000146, PMID 10966060.

11. Tobe SW, Noble-Topham SE, Andrulis IL, Hartwick RW, Skorecki KL, Warner E. Expression of the multiple drug resistance gene in human renal cell carcinoma depends on tumor histology, grade, and stage. Clin Cancer Res. 1995;1(12):1611-5. PMID 9815963.

12. Volm M, Mattern J, Samsel B. Overexpression of P-glycoprotein and glutathione S-transferase-pi in resistant non-small cell lung carcinomas of smokers. Br J Cancer. 1991;64(4):700-4. doi: 10.1038/bjc.1991.384, PMID 1680367.

13. Ng IO, Lam KY, Ng M, Kwong DL, Sham JS. Expression of P-glycoprotein, a multidrug-resistance gene product, is induced by radiotherapy in patients with oral squamous cell carcinoma. Cancer. 1998;83(5):851-7. doi: 10.1002/(sici)10970142(19980901)83:5<851::aid-cncr8>3.0.co;2-I, PMID 9731886.

14. Wartenberg M, Gronczynska S, Bekhite MM, Saric T, Niedermeier W, Hescheler J, et al. Regulation of the multidrug resistance transporter P-glycoprotein in multicellular prostate tumor spheroids by hyperthermia and reactive oxygen species. Int J Cancer. 2005;113(2):229-40. doi: 10.1002/ ijc.20596, PMID 15389514.

15. Bebek G, Bennett KL, Funchain P, Campbell R, Seth R, Scharpf J, et al Microbiomic subprofiles and MDR1 promoter methylation in head and neck squamous cell carcinoma. Hum Mol Genet. 2012;21(7):1557-65. doi: 10.1093/ hmg/ddr593, PMID 22180460.

16. Lee $\mathrm{CH}$, Bradley G, Ling V. Increased P-glycoprotein messenger RNA stability in rat liver tumors in vivo. J Cell Physiol. 1998:177(1):1-12. doi: 10.1002/(SICI)10974652(199810)177:1<1::AID-JCP1>3.0.CO;2-R, PMID 9731740.

17. Lee $\mathrm{CH}$, Rehaume VE, Shandro J. Identification of in vivo P-glycoprotein mRNA decay intermediates in normal liver but not in liver tumors. J Cell Physiol. 2005;204(2):638-45. doi: 10.1002/jcp.20313, PMID 15744753.

18. Yan PW, Huang XE, Yan F, Xu L, Jiang Y. Influence of MDR1 gene codon 3435 polymorphisms on outcome of platinum-based chemotherapy for advanced Non-small cell lung cancer. Asian Pac J Cancer Prev. 2011;12(9):2291-4. PMID 22296372.

19. El-Khayat ZA, Fathy SA, Nabih HK, El-Toukhy SE, Atef AA, EIShaer MA Expression of drug resistance-related proteins; survivin and P-glycoprotein in astrocytic Tumors and their correlation with Malignant Grade and to each other. New York. Sci J. 2011;4(11):49-54.

20. Marroni M, Agrawal ML, Kight K, Hallene KL, Hossain M, Cucullo L, et al. Relationship between expression of multiple drug resistance proteins and p53 tumor suppressor gene proteins in human brain astrocytes. Neuroscience. 2003;121(3):605-17. doi: 10.1016/s0306-4522(03)00515-3, PMID 14568021

21. Oda $Y$, Saito $T$, Tateishi N, Ohishi $Y$, Tamiya $S$, Yamamoto $H$, et al. ATP-binding cassette superfamily transporter gene expression in human soft tissue sarcomas. Int J Cancer. 2005:114(6):854-62. doi: 10.1002/ijc.20589, PMID 15609299.

22. Goff BA, Paley PJ, Greer BE, Gown AM. Evaluation of chemoresistance markers in women with epithelial ovarian carcinoma. Gynecol Oncol. 2001:81(1):18-24 doi: 10.1006/gyno.2000.6105, PMID 11277644

23. Warmann SW, Fuchs J. Drug resistance in hepatoblastoma. Curr Pharm Biotechnol. 2007:8(2):93-7. doi: 10.2174/138920107780487456, PMID 17430157.

24. Huesker M, Folmer Y, Schneider M, Fulda C, Blum HE, Hafkemeyer P. Reversal of drug resistance of hepatocellular carcinoma cells by adenoviral delivery of anti-MDR1 ribozymes. Hepatology. 2002;36(4 Pt 1):874-84. doi: 10.1053/ jhep.2002.35619, PMID 12297834.

25. Liu J, Hajibeigi A, Ren G, Lin M, Siyambalapitiyage W, Liu Z, et al. Retention of the radiotracers $64 \mathrm{Cu}$-ATSM and 64Cu-PTSM in human and murine tumors is influenced by MDR1 protein expression. J Nucl Med. 2009;50(8):1332-9. doi: 10.2967/jnumed.109.061879, PMID 19617332

26. Ghosh P, Moitra K, Maki N, Dey S. Allosteric modulation of the human P-glycoprotein involves conformational changes mimicking catalytic transition intermediates. Arch Biochem Biophys. 2006;450(1):100-12. doi: 10.1016/j. abb.2006.02.025. PMID 16624245.

27. Maki N, Moitra K, Silver C, Ghosh P, Chattopadhyay AK, Dey S. Modulator Induced Interference in Functional Cross Talk between the Substrate and the ATP sites of Human P-glycoprotein. Biochemistry. 2006;45(8):2739-51. do: 10.1021/bi0521745, PMID 16489767.

28. Maki N, Moitra K, Ghosh P, Dey S. Allosteric Modulation Bypasses the Requirement for ATP Hydrolysis in Regenerating Low Affinity Transition State Conformation of Human P-glycoprotein. J Biol Chem. 2006;281(16):10769-77. doi: $10.1074 /$ jbc.M512579200.

29. Ghanem $\mathrm{Cl}$, Arias A, Novak A, Carpini GD, Villanueva S, Blazquez AG, et al. Acetaminophen-induced stimulation of MDR1 expression and activity in rat intestine and in LS 174T human intestinal cell line. Biochem Pharmacol. 2011;81(2):244-50. doi: 10.1016/j.bcp.2010.10.006, PMID 20955690.

30. Zhang X, Li J, Qiu Z, Gao P, Wu X, Zhou G. Co-suppression of MDR1 (multidrug resistance 1) and GCS (glucosylceramide synthase) restores sensitivity to multidrug resistance breast cancer cells by RNA interference (RNAi). Cancer Biol Ther. 2009;8(12):1117-21. doi: 10.4161/cbt.8.12.8374, PMID 19502811. 
31. Feng FZ, Xiang Y, Cui ZM, Liu ZH, Yang XY. In vivo reversal of multidrug resistance by transduction of human tumor necrosis factor-alpha into drug resistant cell line of choriocarcinoma. Zhonghua Fu Chan Ke Za Zhi. 2003;38(5):294-7. PMID 12895315

32. Cui $Z$, Xiang $Y$, Yang $X$. Establishment of the drug resistant cell line of choriocarcinoma and the reversal of drug resistance by transfection of human interleukin 2 gene. Zhonghua Fu Chan Ke Za Zhi. 2001;36(9):549-53. PMID 11769671.

33. Wartenberg M, Ling FC, Schallenberg M, Bäumer AT, Petrat K, Hescheler J, et al. Down-regulation of intrinsic P-glycoprotein expression in multicellular prostate tumor spheroids by reactive oxygen species. J Biol Chem. 2001;276(20):174208. doi: 10.1074/jbc.M100141200, PMID 11279018.

34. Wartenberg M, Fischer K, Hescheler J, Sauer H. Redox regulation of P-glycoprotein-mediated multidrug resistance in multicellular prostate tumor spheroids. Int J Cancer. 2000;85(2):267-74. doi: 10.1002/(SICI)10970215(20000115)85:2<267::AID-IJC19>3.0.CO;2-H, PMID 10629088.

35. Tabata M, Ohnoshi T, Ueoka H, Kiura K, Kimura I. MDR1 gene expression and treatment outcome in small cell lung cancer: MDR1 gene expression as an independent prognostic factor. Acta Med Okayama. 1993;47(4):243-8. doi: 10.18926/AMO/31553, PMID 8213218.

36. Goldstein LJ, Galski H, Fojo A, Willingham M, Lai SL, Gazdar AF, et al. Expression of a multidrug resistance gene in human cancers. J Natl Cancer Inst. 1989;81(2):116-24. doi: 10.1093/jnci/81.2.116, PMID 2562856.

37. Komdeur R, Molenaar WM, Zwart N, Hoekstra HJ, Van den Berg EVD, Van der graaf WTA. Multidrug resistance proteins in primary and metastatic soft-tissue sarcomas: Down-regulation of P-glycoprotein during metastatic progression. Anticancer Res. 2004;24(1):291-5. PMID 15015610.

Article History: Submission Date : 24-08-2021; Revised Date : 01-10-2021; Acceptance Date : 30-10-2021.

Cite this article: Chakraborty K, Ghosh P. P-glycoprotein Expression in Solid Tumors - An Analysis. Int. J. Pharm. Investigation. 2021;11(4):345-8. 